\title{
Solitary plasmacytoma of the jaw
}

This article was published in the following Dove Press journal:

Journal of Blood Medicine

30 March 2010

Number of times this article has been viewed

\section{Serena Marotta' Pierpaolo Di Micco² \\ 'Haematology Division, Second University of Naples, Italy; ${ }^{2}$ Internal Medicina, Fatebenefratelli Hospital of Naples, Italy}

Correspondence: Pierpaolo Di Micco Internal Medicine Division, Buonconsiglio, Fatebenefratelli, Hospital of Naples, Via San Giacomo dei Capri 69, I-80I 3 I, Naples, Italy

Tel +393398078I46

Email pdimicco@libero

\begin{abstract}
Solitary plasmacytoma may be considered as a rare neoplasm of head and neck and is a different disease compared to multiple myeloma. The main difference is related to the better clinical prognosis of solitary plasmacytoma, which may be clinically silent for several years but several local recurrences may be possible once diagnosed and treated. Clinical signs and symptoms of solitary plasmacytoma are related to bone pain and possible bone fractures. Partial local impairment of local bone function may be present. Bone swelling and local involvement of mucosa and local soft tissue may be revealed. Systemic findings related to the production of monoclonal protein are usually not present and a monoclonal spike in serum electrophoresis may be absent as the monoclonal Bence-Jones protein in the urine. Other systemic dysfunctions as systemic bone marrow involvement with related anemia and absent thrombocytopenia. However, although very rare, solitary plasmacytoma of the jaw may have several clinical presentations and here we review clinical differences reported in the literature.
\end{abstract}

Keywords: solitary plasmacytoma, multiple myeloma, monoclonal, bone function, fracture

\section{Background}

Plasmacytoma is a clonal neopastic disorder of bone marrow that originates from plasma cells. It is the last maturation stage of B lymphocytes. ${ }^{1,2}$ A plasmacytoma is considered a solitary mass of neoplastic monoclonal plasma cells in either bone or soft tissue (ie, extramedullary plasmacytoma). Solitary plasmacytoma may be an isolated disease or the first manifestation of a subsequent multiple myeloma. ${ }^{3,4}$ The isolated form of plasmacytoma seems to have a better prognosis, ${ }^{3-5}$ while in cases of subsequent multiple myeloma the prognosis may be different. ${ }^{6}$ Clonal plasma cells involved in plasmacytoma frequently produce a monoclonal immunoglobulin as well as $\kappa$ or $\lambda$ light chains. ${ }^{7,8}$ A quantitative assay of plasma monoclonal immunoglubulin may be performed during a plasmacytoma and may also reflect tumor growth. ${ }^{9}$ Commonly this described alteration may appear in serum electrophoresis as monoclonal spike in the $\gamma$ area, $\beta$ area, or rarely in $\alpha_{2}$ area. ${ }^{10}$ In cases of light chain production, immunoelectrophoresis may reveal clonal activity in the patient's serum and urine. ${ }^{8}$

Because monoclonal proliferation of plasma cells is localized in the bone marrow during solitary plasmacytoma, bone pain, bone destruction, and pathological fractures represent the most common clinical sign of the disease. ${ }^{5,11}$ Moreover, bone damage may also be responsible for alteration of blood calcium levels, ${ }^{11}$ although this alteration is more frequent in multiple myeloma than in solitary plasmacytoma.

Clinical complications during plasma cell disorders are also related to immunoglobulin production which is responsible for relative immunodeficiency (specifically, antigen 
immune response seems to be reduced during plasmacytoma) and overall kidney damage. ${ }^{1,9,11}$ Kidney damage are principally related to light chains with reduced molecular weight and which are quickly eliminated as the Bence-Jones protein in urine. ${ }^{9,10}$ Immunoglobulin produced by plasmacytoma may be insoluble at cold temperatures, which causes a cryoglobulinemia, ${ }^{5,12}$ in particular if a chronic $\mathrm{C}$ viral hepatitis is associated with the plasmacytoma. ${ }^{5,13,14}$ In these cases, kidney failure may result from reduced immunoglobulin elimination in the urine. ${ }^{9}$ Amyloidosis may be also a consequence of light chain production by plasmacytoma. ${ }^{15}$

A nonsecretory plasmacytoma may rarely be observed, ${ }^{16}$ in which $\kappa$ and $\lambda$ chains are intracytoplasmic and may be detected by immunofluorescence. ${ }^{17}$

However, plasmacytoma may be divided into different clinical forms: soft tissues, extramedullary plasmacytoma, solitary plasmacytoma of bone (ie, localized in a single bone), or multiple myeloma (ie, systemic disease with multiple bone localizations). ${ }^{18}$ Clinical presentation and signs and symptoms are usually different if we consider solitary plasmacytoma and systemic multiple myeloma separately (Table 1).

\section{Solitary plasmacytoma of the jaw}

Solitary plasmacytoma of bone is a separate entity of plasma cell neoplasm and it may located in bone or the extramedullary soft tissue in bone. The localization of solitary plasmacytoma of bone in head and neck is very rare and usually the sinonasal tract is more involved than other bones. ${ }^{19}$ Solitary bone plasmacytoma is very rarely localized in the jaw. Solitary plasmacytoma of the jaw seems to be related to elderly patients and no differences in the frequency were observed between males and females. Clinical signs and symptoms indicated by patients are localized pain and possible bone

Table I Differences between clinical, laboratory, and radiological findings in solitary plasmacytoma of bone and systemic multiple myeloma

\begin{tabular}{lll}
\hline & SPB & MM \\
\hline Bone pain & Present $(+)$ & Present $(+)$ \\
Bone fractures & Present $(+)$ & Present $(++)$ \\
Involvement of local soft tissues & Present $(+)$ & Absent $(-)$ \\
Radiographic alterations & Present $(+)$ & Present $(++)$ \\
Presence of "M" component & Possible $( \pm)$ & Present $(++)$ \\
$\begin{array}{l}\text { Presence of light chains in serum } \\
\text { and/or urine }\end{array}$ & Possible $( \pm)$ & Present $(++)$ \\
Kidney damages & & \\
Altered blood calcium levels & Absent $(-)$ & Present $(+)$ \\
\hline
\end{tabular}

Abbreviations: MM, multiple myeloma; SPB, solitary plasmacytoma of bone. fracture, but also a bone-impaired function is frequently reported. ${ }^{5,11}$ The presence of progressive bone swelling with the involvement of oral mucosa or other soft tissues may be also revealed by physical examination. ${ }^{5,11}$ Asymptomatic solitary bone plasmacytoma of the jaw is very rare but such a clinical form without pain has been described previously. ${ }^{20}$

From an epidemiological point of view, plasma cell neoplasms affect elderly people aged $50-80$ years. ${ }^{5}$ Clinical signs and symptoms may be really poor, therefore it may be very difficult to perform an early diagnosis of solitary plasmacytoma of jaw. Bone pain may be related to other clinical oro-maxillofacial diseases, while the involvement of oral soft tissues may underestimated. ${ }^{11}$ Frequently, only after a radiologic approach may solitary plasmacytoma of jaw be clinically suspected. ${ }^{19,21}$ In fact, because the main clinical signs of solitary plasmacytoma may be summarized in localized bone pain and bone alterations, X-ray examination usually shows joint alteration, well defined radiographic lesions, and bone fractures. ${ }^{5,19,21}$ Pisano and colleagues reported a localized radiolucency on the roots or apices of nearby teeth as radiographic signs of the disease. ${ }^{11,21}$ Moreover, laboratory signs are immunoglobulin production, if the secretory component is present (ie, monoclonal gammopathy in serum electrophoresis, light chain production detectable in serum and/or urine, cryoglobulinemia), blood calcium alterations, and kidney dysfunction. ${ }^{1,9}$ Amyloidosis ${ }^{15}$ and POEMS (polyneuropathy, organomegaly, endocrinopathy, multiple myeloma, and skin changes) syndrome ${ }^{22}$ may be observed only as a complication of secretory plasmacytoma. In cases of nonsecretory plasmacytoma, light chain production is rare, while intracytoplasmic monoclonal immunoglobulin production is observed. ${ }^{16,17}$

Bone marrow aspirate and/or bone marrow biopsy are normal in solitary plasmacytoma, and are usually diagnostic of multiple myeloma (presence of more than $15 \%$ of neoplastic plasma cells). ${ }^{9}$ Therefore, only a localized bone biopsy or surgical approach directed to damaged bone allows the identification of a solitary plasmacytoma.

On the other hand, other systemic alterations as hypocalcemia, hypecalcemia, anemia, leukopenia, thrombocytopenia, and impaired renal function are absent in solitary plasmacytoma, but are usually present in multiple myeloma.

\section{Diagnostic criteria for solitary bone plasmacytoma}

Criteria for identifying solitary bone plasmacytoma vary among authors. However, the current criteria to perform a diagnosis of solitary plasmacytoma are the following: ${ }^{18}$ isolated area of bone destruction due to clonal plasma cells, bone marrow plasma cell infiltration not exceeding $5 \%$ of 
all nucleated cells, absence of further osteolytic bone lesions or other tissue involvement (ie, no evidence of systemic plasmacytoma), absence of anemia, hypercalcemia, or renal impairment attributable to myeloma, low concentrations of serum or urine monoclonal protein (ie, myeloma protein), or preserved levels of immunoglobulins. ${ }^{18}$

\section{Clinical aspects of solitary plasmacytoma of jaw}

Jaw is a very rare localization of solitary plasmacytoma of head and neck, ${ }^{19}$ and its symptoms may be underestimated because they may be considered aspecific. Therefore, clinical suspicion of solitary plasmacytoma is difficult and particular aspects may differ in laboratory and histological findings. Specific symptoms to suspect a diagnosis of solitary plasmacytoma localized in a unique bone segment are: pain, impairment of bone function and movements, presence of bone swelling with or without local erosion, involvement of local mucosa or tissues, and other systemic symptoms are lacking. The clinical presentation of solitary plasmacytoma of jaw without pain is very rare, but it has been reported. ${ }^{20}$

Such abnormalities may be found in laboratory data, mainly regarding the possible secretion of monoclonal protein. Radiologic abnormalities are more common and may be found on the roots or apices of nearby teeth as reported by Pisano and colleagues. ${ }^{11}$ Other particular clinical aspects of solitary plasmacytoma of jaw were reported in several cases in the literature. Lo Munzo and colleagues reported a solitary plasmacytoma localized in the jaw of a 53-year-old man. The histological examination of the specimen was positive for a plasmacytoma with anaplastic appearance and the only clinical sign was localized pain. ${ }^{23}$ The patient was free of recurrent primary disease and was not affected by multiple localization. ${ }^{23}$ In another case reported by our group, a 76-year-old woman was affected by solitary plasmacytoma of the left jaw and chronic hepatitis $\mathrm{C}$ infection. Her clinical presentation was with pain and localized swelling in the jaw. Blood examination showed an increase of gammaglobulin $(1.71 \mathrm{~g} / \mathrm{dL})$ but was negative for serum monoclonal immunoglobulin spike. Histological examination of the jaw showed massive diffuse stromal infiltration by monoclonal binucleate and trinucleate plasmacytes with basophilic cytoplasm, hypodense chromatin, and a nucleus with multiple nucleoli. A nonsecretory plasmacytoma was diagnosed. ${ }^{5}$ Canger and colleagues reported a case of a 76-year-old woman affected by isolated plasmacytoma of the mandibular anterior region. ${ }^{20}$ She underwent a surgical interventional for a hip prothesis and an isolated plasmacytoma of the jaw was diagnosed two months before during presurgical examinations. Local radiotherapy was performed and there was no evidence of additional lesions, nor bone marrow involvement, during the first radiographic follow up. Histological features were numerous plasma cells with abundant cytoplasma and eccentrically located nuclei.

Soares Pinto and colleagues reported a case of a 65 -year-old Black woman with intraoral lesions. ${ }^{24} \mathrm{~A}$ physical examination disclosed a bluish-red swelling in the left canine area of the maxilla. Histological features were sheets of atypical plasma cells and monoclonal staining for $\kappa$ chains was positive. Serum electrophoresis revealed an immunoglobulin $\mathrm{G}$ monoclonal gammopathy. Bone marrow examination displayed more than $50 \%$ plasmacytosis, but Bence-Jones protein was not found in the urine. ${ }^{24}$ However, abnormalities in light chain secretions by monoclonal plasma cells were also reported by other authors. Dhaif and colleagues reported a case of a solitary plasmocytoma on the left angle of the mandible in a 46-year-old man. ${ }^{25}$ Microscopic examination showed extensive infiltration of bone by monoclonal plasma cells, with some atypical and binucleate forms. The cells demonstrated $\lambda$ light chain restriction. Serum and urine protein electrophoresis disclosed a monoclonal peak, identified as immunoglobulin $\mathrm{G}$, and Bence - Jones protein was discovered. ${ }^{25}$ In the same report, Dhaif and colleagues described a case of plasmacytoma on the right maxilla obliterating the antrum and extending into the nose in a 53-year-old man. ${ }^{25}$ A biopsy was performed and the diagnosis of plasmacytoma was confirmed after local irradiation with limited surgical approaches. The patient did not reveal recurrences in more than 10 years follow-up, which confirms that solitary plasmaytoma is associated with a better prognosis compared to multiple myeloma..$^{25}$

\section{Prognosis}

The median survival rate of a solitary plasmacytoma is longer than in multiple myeloma ${ }^{19,25-27}$ because of the absence of diffused bone marrow alterations, kidney damage, hypercalcemia, and related bone fractures. ${ }^{5,26-28}$ However, full clinical remission is unusual..$^{5,26-28}$ The prognosis of solitary plasmacytoma could be worse if recurrence is present as in cases of evolution toward systemic disease (multiple myeloma). ${ }^{9}$

Similarly, the evolution of solitary plasmacytoma of the jaw is usually better if there are no recurrences after treatment (local surgery, local irradiation, systemic chemotherapy, or a combination) or an evolution toward systemic plasmacytoma. According to a long-term outcome analysis reported in the literature, radiation, chemotherapy, surgery, or a combined radiation and surgical approach gave good outcomes with a low rate of local recurrence. ${ }^{19,26-28}$ Nearly $80 \%$ of patients did not show local recurrence after five years while $20 \%$ developed multiple myeloma. ${ }^{19}$ 
Pharmacological toxicity should be considered in treated patients, in particular if melphalan is used, because relevant side effects such as acute leukemia and other complications such as sepsis (a well known complication of chemotherapyinduced neutropenia) may appear. ${ }^{29-30}$ Moreover, thrombosis has been described as a complication for patients treated with thalidomide in particular. ${ }^{31}$

Solitary plasmacytoma is an isolated disease and the mortality of affected patients may be related to other unrelated diseases such as cardiovascular disease.

\section{Disclosures}

The authors report no conflicts of interest in this work.

\section{References}

1. William JW, Beutker E, Erslev AJ, Licthmann MA. Hematology. New York, NY: McGraw Hill, Inc.; 1990:1140-1147.

2. Diebold J. World Health Organization classification of malignant lymphomas. Exp Oncol. 2001;23:101-103.

3. Corwin JD, Lindberg RD. Solitary plasmacytoma of bone vs extramedullary plasmacytoma and their relationship with multiple myeloma. Cancer. 1979;43:1007-1013.

4. Knowling MA, Harwood AR, Bergsagel DE. Comparison of extramedullary plasmacytoma with solitary and multiple plasma cell tumor of bone. J Clin Oncol. 1983;1:255-262.

5. Di Micco P, Niglio A, Torella R, Di Micco B. Solitary plasmacytoma of the jaw occurring in a elderly woman affected by hepatitis $\mathrm{C}$ virus infection: a case report. Tumori. 2002;88:421-424.

6. Ferrer Albiach C, Ferrer Albiach E, Fernandez Izquierdo A, Pinzo Bsach J, Ramos Fernandez V, Rancho Tomas R. Solitary plasmocytoma of the mandible. Report of one case and review of the literature. An Otorrinolaringol Ibero Am. 1995;22:609-618.

7. Huang JS, Ho YP, Ho KY, et al. Multiple myeloma with oral manifestation report of two cases. Kaoshiung J Med Sci. 1997;13:388-394.

8. Cotticelli G, Di Micco P, Mastroianni M, Ciavattone A, Bartiromo D, Torella R. Long term survival of a young man with $\lambda$-IgD plasmacytoma. Exp Oncol. 2003;25:313-314.

9. Longo DL. Plasma cell disorders. In: Fauci AS, Braunwald E, Kasper DL, et al. editors. Harrison's Principles of Internal Medicine. 15th edition. New York, NY: McGraw Hill, Inc.; 2001. p. 727-733.

10. Kadokura M, Tanio N, Nonaka M, et al. A surgical case of solitary plasmacytoma of rib origin with biclonal gammopathy. Jpn J Clin Oncol. 2000;30:191-195.

11. Pisano JJ, Coupland R, Chen SY, Miller AS. Plasmacytoma of the oral cavity and jaws: a clinicpathological study of 13 cases. Oral Surg Oral Med Oral Pathol Oral Radiol Endod. 1997;83:265-271.

12. Persico M, De Marino FA, Di Giacomo Russo G, et al. Prevalence and incidence of cryoglobulins in hepatitis $\mathrm{C}$ virus-related chronic hepatitis patients: a prospective study. Am J Gastroenterol. 2003;98:884-888.
13. Fornasieri A, Bernasconi P, Ribero ML, et al. Hepatitis C virus (HCV) in lymphocytes subsets and in B lymphocytes expressing rheumatoid factor cross-reacting idiotype in type II mixed cryoglobulinaemia. Clin Exp Immunol. 2000;122:400-403.

14. De Vita S, Sansonno D, Dolcetti R, et al. Hepatitis C virus within a malignant lymphoma lesion in the corse of type II mixed cryoglobulinaemia. Blood. 1995;86:1887-1992.

15. Ing EB, Woolf IZ, Younge BR, Bjornsson J, Leavitt JA. Systemic amyloidosis with temporal artery involvement mimcking temporal arteritis. Ophtalmic Surg Lasers. 1997;28:328-331.

16. River GL, Tewksbury DA, Fudenberg HH. "Nonsecretory" multiple myeloma. Blood. 1972:40:204-206.

17. Hurez D, Preud' Homme JL, Seligmann M. Intracellular "monoclonal" immunoglobulin in non-secretory human myeloma. J Immunol. 1970;104:263-264.

18. Fanning SR, Hussein MA. Plasmacytoma extramedullary. 2009. Available from: http://www.medscape.com/px/trk.svr/emedsearch?exturl=http:// emedicine.medscape.com/article/207233-overview. Accessed on January 10, 2010.

19. Bachar G, Goldstein D, Brown D, et al. Solitary extramedullary plasmacytoma of the head and neck-long-term outcome analysis of 68 cases. Head Neck. 2008;30:1012-1019.

20. Canger EM, Celenk P. Mandibular involvement of solitary plasmacytoma: a case report. Med Oral Patol Oral Cir Bucal. 2007;12:E7-E9.

21. Scutellari PN, Orzincolo C. Bone disease in multiple myeloma, Analysis of 253 controlled cases, with reappraisal of diagnostic criteria and current imaging tecqniques. Radiol Med (Torino). 1993;85:235-246.

22. Singh D, Wadhwa J, Kumar L, Raina V, Agarwal A, Kochupillai V. POEMS syndrome: experience with fourteen cases. Leuk Lymphoma. 2003;44:1749-1752.

23. Lo Munzo L, Pannone G, Bucci P. Early clinical diagnosis of solitary plasmacytoma of the jaws: a case report with a six year follow-up. Int J Oral Maxillofac Surg. 2001;30(6):558-560.

24. Soares Pinto LS, Campagnoli EB. Maxillary lesion presenting as a first sign of multiple myeloma: case report. Med Oral Patol Oral Cir Bucal. 2007;12:E344-E347.

25. Dhaif G, Sleeman D. Solitary plasmacytoma of the jaws report of two cases. The Saudi Dental Journal. 1996;8(2):92-95.

26. Dores GM, Landgren O, McGlynn KA, Curtis RE, Linet MS, Devesa SS. Plasmacytoma of bone, extramedullary plasmacytoma, and multiple myeloma: incidence and survival in the United States, 1992-2004. Br J Haematol. 2009; 144:86-94.

27. Bolek M, Sztuk S. Ten years survival of solitary plasmacytoma. Pol Merkuriusz Lek. 2001;11:160-161.

28. Knobel D, Zouhair A, Tsang RW, et al. Rare Cancer Network. Prognostic factors in solitary plasmacytoma of the bone: a multicenter Rare Cancer Network study. BMC Cancer. 2006;6:118.

29. Piccinini L, Artusi T, Bonacorsi G, Arigliano V. Acute leukemia of plasmablastic type as terminal phase of multiple myeloma. Haematologica. 2002;87:EIM04.

30. Crawford J, Dale DC, Lyman GH. Chemotherapy-induced neutropenia: risks, consequences, and new directions for its management. Cancer. 2004;100:228-237.

31. Rodeghiero F, Elice F. Thalidomide and thrombosis. Patophysiol Haemost Thromb. 2003;33(Suppl 1):15-18.

\section{Publish your work in this journal}

The Journal of Blood Medicine is an international, peer-reviewed, open access, online journal publishing laboratory, experimental and clinical aspects of all topics pertaining to blood based medicine including but not limited to: Transfusion Medicine; Blood collection, Donor issues, Transmittable diseases, and Blood banking logistics; Immunohematology; Artificial and alternative blood

\section{Dovepress}

based therapeutics; Hematology; Biotechnology/nanotechnology of blood related medicine; Legal aspects of blood medicine; Historical perspectives. The manuscript management system is completely online and includes a very quick and fair peer-review system. Visit http://www.dovepress.com/ testimonials.php to read real quotes from published authors. 